\section{Fatores associados ao início da vida sexual de adolescentes matriculados em uma unidade de saúde da família da zona leste do Município de São Paulo, Brasil}

\author{
Factors associated with sexual debut among \\ adolescents enrolled in a family health \\ unit in East Side São Paulo, Brazil
}

\author{
1 Escola de Enfermagem, \\ Universidade de São Paulo, \\ São Paulo, Brasil. \\ 2 Faculdade de Saúde \\ Pública, Universidade de \\ São Paulo, São Paulo, Brasil. \\ Correspondência \\ A. L. V. Borges \\ Departamento de \\ Enfermagem em Saúde \\ Coletiva, Escola de \\ Enfermagem, Universidade \\ de São Paulo. \\ Rua Dr. Enéas de \\ Carvalho Aguiar 419, \\ São Paulo, SP \\ 05403-000, Brasil. \\ alvilela@usp.br
}

\begin{abstract}
This study aimed to analyze the individual and family factors associated with sexual debut among adolescents. From June to December 2002, a cross-sectional study was conducted with 383 15-19-year-old single adolescents enrolled in a family health unit on the East Side of the city of São Paulo, Brazil. Multiple logistic regression analysis was conducted separately for males and females. Dating and age were positively associated with sexual debut for both boys and girls. Parental factors were only associated with male sexual debut, while factors related to siblings and housing were only associated with female sexual debut. Thus, dating and family factors like parents' opinions on sexual practices in adolescence and having a sibling with a history of teenage pregnancy are aspects that need to be incorporated into reproductive and sexual health promotion policies targeting adolescents, since they appear as determinants of sexual debut among these young people.
\end{abstract}

Sexual Behaviour; Sexual and Reproductive Health; Adolescent
Ana Luiza Vilela Borges 1

Maria do Rosário Dias de Oliveira Latorre 2 Néia Schor 2

\section{Introdução}

Entre as experiências corporais, emocionais, afetivas e amorosas que ocorrem no processo de desenvolvimento da sexualidade na adolescência, a primeira relação sexual é considerada um marco na vida do indivíduo, sendo inclusive marcada pela expressão popular "a primeira vez nunca se esquece". Não se pode negar que, do ponto de vista da saúde reprodutiva e sexual, ao mesmo tempo em que marca uma passagem para a vida adulta, também insere o adolescente, de forma mais intensa, no grupo vulnerável às doenças sexualmente transmissíveis (DST) e AIDS, à gestação não planejada e ao aborto.

A iniciação sexual não tem ocorrido de forma homogênea entre homens e mulheres, grupos sociais ou entre gerações, sugerindo que um conjunto de fatores complexos pode determinar a tomada de decisão em iniciar a vida sexual ou adiar esse evento para um momento considerado mais adequado. Numerosos fatores têm sido descritos como associados ao início da vida sexual, entre eles algumas características aqui nomeadas individuais, tais como idade, cor, sexo, religião, escolaridade e a situação de trabalho, bem como aquelas aqui consideradas familiares, ou seja, relativas à comunicação e ao relacionamento entre pais e filhos, à supervisão parental e à estrutura familiar. Outros aspectos discutidos na literatura, principalmente internacional, referem-se às influências que os 
pares exercem no comportamento sexual dos adolescentes.

A literatura tem mostrado que, na maioria das vezes, a iniciação sexual de adolescentes do sexo masculino ocorre mais precocemente que a do sexo feminino 1,2 e que os indivíduos negros, os ausentes do sistema educacional ou que tenham baixa escolaridade, pertencentes a grupos sociais mais desfavorecidos, trabalhadores e sem religião são aqueles mais propensos a iniciar-se sexualmente na adolescência 3,4,5,6,7,8. A idade também mostrou-se positivamente associada à primeira experiência sexual nessa fase 8,9 , o que parece revelar que, mesmo sendo um evento que ocorre mais freqüentemente nesse período do ciclo vital, é um processo gradual, que vai ganhando dimensão ao longo da adolescência.

Outros fatores descritos como associados à iniciação sexual de adolescentes referem-se a aspectos familiares, basicamente divididos em três itens: a estrutura familiar, a comunicação entre pais e filhos e o monitoramento sobre os adolescentes exercido pelos pais. A influência da família parece ser mediada pela transmissão de valores dos pais aos filhos, e os pais podem exercer tal influência por meio de atitudes de aprovação ou reprovação de algum tipo de comportamento ou por meio de seu próprio comportamento, tido como exemplo do que parece ser aceitável ou inaceitável. Assim, morar com apenas um dos pais ou com nenhum deles parece elevar a chance de iniciação sexual entre adolescentes 8,9.

Por sua vez, Romer et al. 7 enfatizaram que o maior monitoramento parental foi associado com a postergação do início da vida sexual. E, ainda, Miller et al. 10 referiram que os diálogos mantidos entre pais e filhos sobre assuntos relativos a sexo foram associados ao adiamento da primeira relação sexual.

Diante disso, esta investigação toma como hipótese que os pais e as mães têm um papel preponderante na iniciação sexual de seus filhos adolescentes por compreenderem um espaço singular da socialização do indivíduo e transmitirem continuamente seus valores aos filhos. Ressalte-se, também, que as pesquisas brasileiras sobre o comportamento sexual e reprodutivo de adolescentes pouco têm incorporado suas escolhas sob a ótica da influência familiar, o que tornaria a compreensão do papel dos pais de adolescentes no início de sua vida sexual um componente essencial para ampliação do conhecimento e atuação no campo da saúde coletiva, mais especificamente da saúde sexual e reprodutiva.

\section{Objetivo}

Descrever os aspectos individuais e familiares associados ao início da vida sexual de adolescentes de 15 a 19 anos de idade, matriculados em uma unidade básica de saúde da família do Município de São Paulo, Brasil.

\section{Método}

Foi conduzido um estudo do tipo transversal em uma amostra representativa de adolescentes entre 15 e 19 anos de idade, moradores da área adscrita de uma unidade de saúde da família da zona leste do Município de São Paulo. Os indivíduos foram selecionados por amostragem sistemática sem reposição, a partir de uma listagem obtida por meio do Sistema de Informação da Atenção Básica (SIAB). A listagem foi ordenada de acordo com o número da micro-área e, posteriormente, com o número das famílias cadastradas no Programa Saúde da Família (PSF) que tinham ao menos um adolescente entre 15 e 19 anos de idade. Com base na estimativa de que, em 1998, $60 \%$ dos adolescentes brasileiros entre 16 e 19 anos já haviam tido ao menos uma relação sexual 2 , o tamanho da amostra foi calculado, com erro máximo em valor absoluto de 5\% e com nível de confiança de $95 \%$, tendo sido ajustado por um fator de correção para população finita. Ainda, considerando a possibilidade de perdas, foram acrescidos $30 \%$ para que não houvesse redução do tamanho da amostra. No caso de famílias com mais de um adolescente entre 15 e 19 anos de idade, um sorteio foi realizado e apenas um adolescente foi entrevistado.

No sentido de contemplar todas as famílias selecionadas na amostragem sistemática, foram entrevistados 406 adolescentes entre 15 e 19 anos de idade, por meio de um formulário estruturado e pré-testado, entre junho e dezembro de 2002. Para dar conta do número de entrevistas que deveriam ser realizadas, formou-se uma equipe com duas entrevistadoras, além da pesquisadora responsável (que realizou mais da metade das entrevistas). As duas entrevistadoras foram treinadas para a aplicação do instrumento e para a abordagem do adolescente, sendo acompanhadas semanalmente com muita atenção. Todos os instrumentos preenchidos foram revisados em conjunto com a entrevistadora e, posteriormente, foram anotadas as respostas pré-codificadas na coluna para digitação do banco de dados.

A confiabilidade dos dados coletados pelas duas entrevistadoras foi checada tanto por meio da comparação dos dados sócio-demográficos dos adolescentes com as informações contidas 
na ficha de cadastro do SIAB, quanto por meio de uma visita domiciliar posterior à entrevista para a confirmação dos dados preenchidos em mais da metade das entrevistas.

As entrevistas ocorreram predominantemente no próprio domicílio do adolescente, mas também em outros locais por ele escolhido, tais como casa de vizinhos/parentes, espaço público, centro de juventude e outros.

Os consentimentos foram obtidos com os responsáveis pelo jovem ou com ele próprio, desde que com idade igual ou superior a 18 anos. Esta pesquisa foi aprovada pelo Comitê de Ética em Pesquisa da Faculdade de Saúde Pública, Universidade de São Paulo.

Considerando o objetivo do estudo, optou-se por excluir os indivíduos que já haviam passado por uma união conjugal, pois se considerou que as experiências amorosas, sexuais e reprodutivas vivenciadas por adolescentes que já passaram por um processo de união, assim como seu grau de autonomia, são muito diversas das daqueles que são solteiros, e sua análise conjunta poderia acarretar viés nos resultados e conclusões desta investigação. Portanto, a população de estudo foi finalmente constituída de 383 adolescentes solteiros entre 15 e 19 anos de idade.

A variável dependente foi o início da vida sexual (não/sim). As variáveis explicativas foram divididas em individuais, relativas aos próprios adolescentes, e familiares, relativas aos pais e mães, irmãos e opinião dos adolescentes acerca dos valores e atitudes paternos e maternos no tocante à sexualidade na adolescência.

Foram considerados como pais e mães tanto os pais biológicos quanto os padrastos e madrastas, desde que estivessem coabitando com o adolescente no momento da entrevista. No entanto, na apresentação dos resultados, foram suprimidas as categorias "não mora com a mãe" e "não mora com o pai" porque nenhuma delas mostrou significância estatística na análise dos dados.

A digitação do banco de dados foi realizada utilizando o programa Epi Info 6.04 (Centers for Disease Control and Prevention, Atlanta, Estados Unidos). Os dados foram analisados por meio de regressão logística múltipla, utilizando o programa SPSS (SPSS Inc., Chicago, Estados Unidos) para Windows versão 11.0.

Inicialmente, os aspectos investigados foram agrupados por blocos - individuais, familiares e relacionamento pais-filhos - e analisados por meio de regressão logística univariada. Apenas as variáveis que apresentaram uma associação de $\mathrm{p}<0,20$ com o início da vida sexual foram analisadas na segunda etapa, ainda em blocos, por meio de regressão logística múltipla. A par- tir dos modelos elaborados para cada um dos blocos iniciais, foi elaborado um modelo multivariado final, com as variáveis que obtiveram $\mathrm{p}<0,05$.

Partindo do princípio de que homens e mulheres têm propensões diferentes para o engajamento sexual, decidiu-se que a análise dos fatores associados seria conduzida separadamente para os sexos.

\section{Resultados}

Os 383 adolescentes solteiros dividiram-se em 203 mulheres (53\%) e 180 homens (47\%). A idade média e mediana verificada foi igual entre os sexos, sendo 16,7 anos e 17,0 anos, respectivamente. Um pouco menos da metade dos adolescentes já havia iniciado a vida sexual, sendo $45,6 \%$ dos homens e 40,4\% das mulheres.

A maior parte dos adolescentes referiu-se como de cor parda ou preta (agrupada em negra). A religião predominante foi a católica, mas ressaltese que mais homens relataram não ter qualquer religião do que mulheres. Uma proporção considerável dos adolescentes encontrava-se ausente do sistema educacional e $27,2 \%$ dos homens e $15,8 \%$ das mulheres relataram estar trabalhando fora de casa, formal ou informalmente. Aproximadamente um em cada quatro adolescentes habitava um domicílio ocupado, ou seja, invadido. Ao se considerar a coabitação, verificou-se que a maior parte dos adolescentes morava com ambos os pais. Os dados relacionados aos adolescentes estão mais bem descritos na Tabela 1 (sexo masculino) e Tabela 2 (sexo feminino).

Em relação aos pais e mães dos adolescentes entrevistados (Tabelas 3 e 4), observa-se que tinham baixa escolaridade. Ao redor de $35 \%$ das mães tiveram o primeiro filho ainda na adolescência, ou seja, antes dos 19 anos de idade.

De acordo com as Tabelas 3 e 4, os pais e mães dos adolescentes de sexo masculino mais freqüentemente concordaram que adolescentes tenham vida sexual do que os pais e mães das adolescentes. Por outro lado, os pais e mães das garotas foram proporcionalmente mais favoráveis a que suas filhas iniciassem a vida sexual apenas após o casamento do que os pais e mães dos garotos.

Os adolescentes de ambos os sexos revelaram ter mais abertura para conversar sobre sexo com suas mães do que com seus pais. No que diz respeito à postura materna e paterna em relação a passeios e namoros, a maior parte dos entrevistados revelou considerar seus pais e mães liberais ou meio-termo, aqui denominados "não rígidos". 
Tabela 1

Descrição de adolescentes do sexo masculino conforme variáveis individuais, proporção de início da vida sexual e análise bruta entre início da vida sexual e preditores. São Paulo, Brasil, 2002.

\begin{tabular}{|c|c|c|c|c|c|}
\hline Variável & $\mathbf{n}$ & $\%$ & Início da vida sexual & OR & IC95\% \\
\hline \multicolumn{6}{|l|}{ Idade (anos) } \\
\hline 15 & 44 & 24,4 & 20,5 & 1,0 & - \\
\hline 16 & 42 & 23,3 & 28,6 & 1,5 & $0,6-4,2$ \\
\hline 17 & 42 & 23,3 & 64,3 & 6,9 & $2,7-18,4$ \\
\hline 18 & 28 & 15,6 & 67,9 & 8,2 & $2,8-24,2$ \\
\hline 19 & 24 & 13,3 & 62,5 & 6,4 & $2,1-19,6$ \\
\hline \multicolumn{6}{|l|}{ Cor } \\
\hline Negra & 121 & 67,2 & 45,5 & 1,0 & - \\
\hline Não-negra & 59 & 32,8 & 45,8 & 0,9 & $0,5-1,8$ \\
\hline \multicolumn{6}{|l|}{ Religião } \\
\hline Católica & 97 & 53,9 & 51,5 & 1,0 & - \\
\hline Evangélica/Outras & 39 & 21,7 & 27,8 & 0,4 & $0,2-0,8$ \\
\hline Sem religião & 44 & 24,4 & 47,7 & 0,8 & $0,4-1,7$ \\
\hline \multicolumn{6}{|l|}{ Estudo atual } \\
\hline Não & 40 & 22,2 & 75,0 & 5,1 & $2,3-11,2$ \\
\hline $\operatorname{Sim}$ & 140 & 77,8 & 37,1 & 1,0 & - \\
\hline \multicolumn{6}{|l|}{ Trabalho atual } \\
\hline Não & 131 & 72,8 & 37,4 & 1,0 & - \\
\hline Sim & 49 & 27,2 & 67,3 & 3,4 & $1,7-6,9$ \\
\hline \multicolumn{6}{|l|}{ Domicílio } \\
\hline Próprio & 114 & 63,3 & 44,7 & 1,0 & - \\
\hline Ocupado & 47 & 26,1 & 52,6 & 0,9 & $0,5-1,8$ \\
\hline Alugado & 19 & 10,6 & 44,7 & 1,4 & $0,5-3,6$ \\
\hline \multicolumn{6}{|l|}{ Coabitação } \\
\hline Ambos os pais & 110 & 61,1 & 44,5 & 1,0 & - \\
\hline Somente com a mãe & 54 & 30,0 & 50,0 & 1,2 & $0,6-2,4$ \\
\hline Somente com o pai & 8 & 4,4 & 25,0 & 0,4 & $0,1-2,2$ \\
\hline Nenhum dos pais & 8 & 4,4 & 50,0 & 1,2 & $0,3-5,2$ \\
\hline \multicolumn{6}{|l|}{ Namoro anterior } \\
\hline Não & 21 & 11,7 & 9,5 & 1,0 & - \\
\hline Sim & 159 & 88,3 & 50,3 & 9,6 & $2,2-42,7$ \\
\hline \multicolumn{6}{|l|}{ Namoro atual } \\
\hline Não & 137 & 76,1 & 35,0 & 1,0 & - \\
\hline Sim & 43 & 23,9 & 79,1 & 7,0 & $3,1-15,8$ \\
\hline \multicolumn{6}{|c|}{ Maior parte dos amigos já iniciou a vida sexual * } \\
\hline Não & 76 & 42,7 & 36,8 & 1,0 & - \\
\hline Sim & 98 & 56,3 & 54,1 & 2,0 & $1,1-3,7$ \\
\hline
\end{tabular}

* Excluídos seis indivíduos que não souberam responder.

As Tabelas de 1 a 4 apresentam também as análises brutas para a ocorrência do início da vida sexual e as diversas variáveis estudadas. Tanto entre os homens quanto entre as mulheres, foi encontrada associação estatisticamente significativa entre o início da vida sexual e a idade, a ausência do sistema educacional, o fato de ter namorado anteriormente e estar namorando, de ter um irmão ou irmã que passou por uma gestação fora de uma união conjugal, a concordância da mãe de que adolescentes tenham vida sexual e o fato de considerar que a mãe não é rígida em relação a namoros e passeios.

Por sua vez, somente entre os adolescentes do sexo masculino, os demais fatores associados foram estar trabalhando, considerar que a maior 
Descrição de adolescentes do sexo feminino conforme variáveis individuais, proporção de início da vida sexual e análise bruta entre início da vida sexual e preditores. São Paulo, Brasil, 2002.

\begin{tabular}{|c|c|c|c|c|c|}
\hline Variável & $\mathbf{n}$ & $\%$ & Início da vida sexual & OR & IC95\% \\
\hline \multicolumn{6}{|l|}{ Idade (anos) } \\
\hline 15 & 46 & 22,7 & 13,0 & 1,0 & \\
\hline 16 & 54 & 26,6 & 29,6 & 2,8 & $0,9-7,9$ \\
\hline 17 & 42 & 20,7 & 61,9 & 10,8 & $3,7-31,2$ \\
\hline 18 & 35 & 17,2 & 57,1 & 8,9 & $2,9-26,4$ \\
\hline 19 & 26 & 12,8 & 53,8 & 7,8 & $2,9-24,6$ \\
\hline \multicolumn{6}{|l|}{ Cor } \\
\hline Negra & 113 & 55,7 & 43,4 & 1,0 & - \\
\hline Não-negra & 90 & 44,3 & 36,7 & 0,7 & $0,4-1,3$ \\
\hline \multicolumn{6}{|l|}{ Religião } \\
\hline Católica & 125 & 61,6 & 40,8 & 1,0 & - \\
\hline Evangélica/Outras & 54 & 26,6 & 34,0 & 0,7 & $0,4-1,4$ \\
\hline Sem religião & 24 & 11,8 & 54,2 & 1,7 & $0,7-4,1$ \\
\hline \multicolumn{6}{|l|}{ Estudo atual } \\
\hline Não & 41 & 20,2 & 63,4 & 3,3 & $1,6-6,7$ \\
\hline Sim & 162 & 79,8 & 34,6 & 1,0 & - \\
\hline \multicolumn{6}{|l|}{ Trabalho atual } \\
\hline Não & 171 & 84,2 & 39,2 & 1,0 & - \\
\hline Sim & 32 & 15,8 & 46,9 & 1,4 & $0,6-2,9$ \\
\hline \multicolumn{6}{|l|}{ Domicílio } \\
\hline Próprio & 139 & 68,5 & 34,5 & 1,0 & - \\
\hline Ocupado & 50 & 24,6 & 56,0 & 2,4 & $1,2-4,7$ \\
\hline Alugado & 14 & 6,9 & 42,9 & 1,4 & $0,5-4,3$ \\
\hline \multicolumn{6}{|l|}{ Coabitação } \\
\hline Ambos os pais & 144 & 70,9 & 37,5 & 1,0 & - \\
\hline Somente com a mãe & 37 & 18,2 & 45,9 & 1,4 & $0,7-2,9$ \\
\hline Somente com o pai & 5 & 2,5 & 80,0 & 6,7 & $0,7-61,2$ \\
\hline Nenhum dos pais & 17 & 8,4 & 41,2 & 1,2 & $0,4-3,2$ \\
\hline \multicolumn{6}{|l|}{ Namoro anterior } \\
\hline Não & 34 & 16,7 & 2,9 & 1,0 & - \\
\hline Sim & 169 & 83,3 & 47,9 & 30,4 & $4,1-227,1$ \\
\hline \multicolumn{6}{|l|}{ Namoro atual } \\
\hline Não & 122 & 60,1 & 22,1 & 1,0 & - \\
\hline Sim & 81 & 39,9 & 67,9 & 7,4 & $3,9-14,0$ \\
\hline \multicolumn{6}{|c|}{ Maior parte dos amigos já iniciou a vida sexual * } \\
\hline Não & 74 & 36,6 & 32,4 & 1,0 & - \\
\hline Sim & 128 & 63,4 & 44,5 & 1,7 & $0,9-3,0$ \\
\hline
\end{tabular}

* Excluídos seis indivíduos que não souberam responder.

parte dos amigos já iniciou a vida sexual, ser filho de mãe que teve o primeiro filho com idade superior aos vinte anos, considerar que o pai e mãe gostariam que iniciasse a vida sexual independentemente do casamento e o pai concordar que adolescentes tenham vida sexual. Entre as mulheres, morar em um domicílio ocupado foi associado ao início da vida sexual.
Na análise múltipla, descrita na Tabela 5, mantiveram associação significativa, tanto entre os homens quanto entre as mulheres, apenas a idade, o namoro atual e o namoro anterior. Ao considerar o sexo masculino isoladamente, observa-se que os fatores associados que permaneceram significativos foram a ausência no sistema educacional, a concordância materna de que 
Descrição de adolescentes do sexo masculino conforme variáveis familiares, proporção de início da vida sexual e análise bruta entre início da vida sexual e preditores. São Paulo, Brasil, 2002.

\begin{tabular}{|c|c|c|c|c|c|}
\hline Variável & $\mathrm{n}$ & $\%$ & Início da vida sexual & OR & IC95\% \\
\hline \multicolumn{6}{|l|}{ Escolaridade materna } \\
\hline Analfabeta & 18 & 10,0 & 66,7 & 1,0 & - \\
\hline Fundamental incompleto & 111 & 61,7 & 38,7 & 0,3 & $0,1-0,9$ \\
\hline Fundamental completo & 23 & 12,8 & 65,2 & 0,9 & $0,2-3,4$ \\
\hline Médio ou mais & 11 & 6,1 & 45,5 & 0,4 & $0,1-1,9$ \\
\hline \multicolumn{6}{|l|}{ Idade materna no primeiro filho (anos) } \\
\hline Até 19 & 69 & 38,3 & 34,8 & 1,0 & - \\
\hline 20 ou mais & 94 & 52,2 & 55,3 & 2,3 & $1,2-4,4$ \\
\hline \multicolumn{6}{|l|}{ Mãe concorda que adolescentes } \\
\hline \multicolumn{6}{|l|}{ tenham vida sexual * } \\
\hline Não & 89 & 54,3 & 29,2 & 1,0 & - \\
\hline Sim & 74 & 45,1 & 66,2 & 4,7 & $2,4-9,2$ \\
\hline \multicolumn{6}{|l|}{ Mãe gostaria que seu filho iniciasse } \\
\hline \multicolumn{6}{|l|}{ a vida sexual * } \\
\hline Somente após o casamento & 55 & 33,5 & 25,5 & 1,0 & - \\
\hline Independentemente do casamento & 106 & 64,6 & 57,5 & 4,0 & $1,9-8,1$ \\
\hline \multicolumn{6}{|l|}{ Abertura para conversar sobre } \\
\hline \multicolumn{6}{|l|}{ sexo com a mãe } \\
\hline Não & 98 & 59,8 & 42,9 & 1,0 & - \\
\hline Sim & 66 & 40,2 & 51,5 & 1,4 & $0,8-2,6$ \\
\hline \multicolumn{6}{|l|}{ Postura materna em relação } \\
\hline \multicolumn{6}{|l|}{ a passeios e namoros } \\
\hline Rígida & 24 & 14,6 & 25,0 & 1,0 & - \\
\hline Não rígida & 140 & 85,4 & 50,0 & 3,0 & $1,1-8,0$ \\
\hline \multicolumn{6}{|l|}{ Escolaridade paterna } \\
\hline Analfabeto & 10 & 5,6 & 40,0 & 1,0 & - \\
\hline Fundamental incompleto & 75 & 41,7 & 44,0 & 1,2 & $0,3-4,5$ \\
\hline Fundamental completo & 18 & 10,0 & 50,0 & 1,5 & $0,3-7,2$ \\
\hline Médio ou mais & 15 & 8,3 & 33,3 & 0,7 & $0,1-3,9$ \\
\hline \multicolumn{6}{|l|}{ Idade paterna no primeiro filho (anos) } \\
\hline Até 19 & 18 & 10,0 & 50,0 & 1,0 & - \\
\hline 20 ou mais & 99 & 55,0 & 42,4 & 0,7 & $0,3-2,0$ \\
\hline \multicolumn{6}{|l|}{ Pai concorda que adolescentes } \\
\hline \multicolumn{6}{|l|}{ tenham vida sexual * } \\
\hline Não & 54 & 45,8 & 25,9 & 1,0 & - \\
\hline Sim & 63 & 53,4 & 57,1 & 3,8 & $1,7-8,4$ \\
\hline \multicolumn{6}{|c|}{ Pai gostaria que seu filho iniciasse a vida sexual * } \\
\hline Somente após o casamento & 33 & 28,0 & 18,2 & 1,0 & - \\
\hline Independentemente do casamento & 82 & 69,5 & 53,7 & 5,2 & $1,9-13,9$ \\
\hline \multicolumn{6}{|c|}{ Abertura para conversar sobre sexo com o pai } \\
\hline Não & 77 & 65,3 & 44,2 & 1,0 & - \\
\hline Sim & 41 & 34,7 & 41,5 & 0,9 & $0,4-1,9$ \\
\hline \multicolumn{6}{|l|}{ Postura paterna em relação a passeios } \\
\hline \multicolumn{6}{|l|}{ e namoros } \\
\hline Rígida & 13 & 11,0 & 46,2 & 1,0 & - \\
\hline Não rígida & 105 & 89,0 & 42,9 & 0,9 & $0,3-2,8$ \\
\hline \multicolumn{6}{|l|}{ Irmão(ã) já engravidou antes de uma união } \\
\hline Não & 105 & 58,3 & 40,0 & 1,0 & - \\
\hline Sim & 42 & 23,3 & 64,3 & 2,7 & $1,3-5,7$ \\
\hline Não tem & 33 & 18,4 & 39,4 & 0,9 & $0,4-2,2$ \\
\hline
\end{tabular}

* Excluídos os ignorados. 
Descrição de adolescentes do sexo feminino conforme variáveis familiares, proporção de início da vida sexual e análise bruta entre início da vida sexual e preditores. São Paulo, Brasil, 2002.

\begin{tabular}{|c|c|c|c|c|c|}
\hline Variável & $\mathrm{n}$ & $\%$ & Início da vida sexual & OR & IC95\% \\
\hline \multicolumn{6}{|l|}{ Escolaridade materna } \\
\hline Analfabeta & 22 & 10,8 & 40,9 & 1,0 & - \\
\hline Fundamental incompleto & 111 & 54,7 & 41,4 & 0,8 & $0,4-2,6$ \\
\hline Fundamental completo & 26 & 12,8 & 34,6 & 0,6 & $0,2-2,5$ \\
\hline Médio ou mais & 21 & 10,3 & 28,6 & 1,4 & $0,2-2,1$ \\
\hline Não mora com a mãe & 22 & 10,8 & 50,0 & 0,7 & $0,4-4,8$ \\
\hline \multicolumn{6}{|l|}{ Idade materna no primeiro filho (anos) } \\
\hline Até 19 & 70 & 34,5 & 45,7 & 1,0 & - \\
\hline 20 ou mais & 110 & 54,2 & 34,5 & 0,6 & $0,3-1,1$ \\
\hline Não mora com a mãe & 22 & 10,8 & 50,0 & 1,2 & $0,5-3,1$ \\
\hline \multicolumn{6}{|c|}{ Mãe concorda que adolescentes tenham vida sexual * } \\
\hline Não & 134 & 74,0 & 34,3 & 1,0 & - \\
\hline Sim & 46 & 25,4 & 54,3 & 2,3 & $1,2-4,5$ \\
\hline \multicolumn{6}{|c|}{ Mãe gostaria que seu filho iniciasse a vida sexual * } \\
\hline Somente após o casamento & 124 & 68,5 & 37,1 & 1,0 & - \\
\hline Independentemente do casamento & 57 & 31,5 & 43,9 & 1,3 & $0,7-2,5$ \\
\hline \multicolumn{6}{|c|}{ Abertura para conversar sobre sexo com a mãe } \\
\hline Não & 87 & 48,1 & 35,6 & 1,0 & - \\
\hline Sim & 94 & 51,9 & 42,6 & 1,3 & $0,7-2,4$ \\
\hline \multicolumn{6}{|c|}{ Postura materna em relação a passeios e namoros } \\
\hline Rígida & 26 & 14,4 & 19,2 & 1,0 & - \\
\hline Não rígida & 155 & 85,6 & 42,6 & 3,1 & $1,1-8,7$ \\
\hline \multicolumn{6}{|l|}{ Escolaridade paterna } \\
\hline Analfabeto & 17 & 8,4 & 47,1 & 1,0 & - \\
\hline Fundamental incompleto & 77 & 37,9 & 40,3 & 0,8 & $0,3-2,1$ \\
\hline Fundamental completo & 26 & 12,8 & 42,3 & 0,8 & $0,2-2,8$ \\
\hline Médio ou mais & 29 & 14,3 & 27,6 & 0,4 & $0,1-1,5$ \\
\hline Não mora com o pai & 54 & 26,6 & 44,4 & 0,9 & $0,3-2,7$ \\
\hline \multicolumn{6}{|l|}{ Idade paterna no primeiro filho (anos) } \\
\hline Até 19 & 19 & 9,4 & 52,6 & 1,0 & - \\
\hline 20 ou mais & 129 & 63,5 & 36,4 & 0,5 & $0,2-1,4$ \\
\hline Não mora com o pai & 54 & 26,6 & 44,4 & 0,7 & $0,3-2,1$ \\
\hline \multicolumn{6}{|c|}{ Pai concorda que adolescentes tenham vida sexual * } \\
\hline Não & 122 & 81,9 & 40,2 & 1,0 & - \\
\hline Sim & 25 & 16,8 & 36,0 & 0,8 & $0,3-2,0$ \\
\hline \multicolumn{6}{|c|}{ Pai gostaria que seu filho iniciasse a vida sexual * } \\
\hline Somente após o casamento & 107 & 71,8 & 37,4 & 1,0 & - \\
\hline Independentemente do casamento & 39 & 26,2 & 41,0 & 1,2 & $0,6-2,5$ \\
\hline \multicolumn{6}{|c|}{ Abertura para conversar sobre sexo com o pai } \\
\hline Não & 111 & 74,5 & 37,8 & 1,0 & - \\
\hline Sim & 37 & 24,8 & 43,2 & 1,2 & $0,6-2,7$ \\
\hline \multicolumn{6}{|c|}{ Postura paterna em relação a passeios e namoros } \\
\hline Rígida & 34 & 22,8 & 35,3 & 1,0 & - \\
\hline Não rígida & 113 & 75,8 & 39,8 & 1,2 & $0,5-2,7$ \\
\hline \multicolumn{6}{|l|}{ Irmão(ã) já engravidou antes de uma união } \\
\hline Não & 112 & 55,2 & 35,7 & 1,0 & - \\
\hline Sim & 63 & 31,0 & 52,4 & 2,0 & $1,1-3,7$ \\
\hline Não tem & 28 & 13,8 & 32,1 & 0,9 & $0,4-2,1$ \\
\hline
\end{tabular}

* Excluídos os ignorados. 
Modelo final de regressão múltipla do início da vida sexual para homens e mulheres. São Paulo, Brasil, 2002.

\begin{tabular}{|c|c|c|c|c|}
\hline \multirow[t]{3}{*}{ Variável } & \multicolumn{4}{|c|}{ Modelo final geral } \\
\hline & \multicolumn{2}{|c|}{ Homens } & \multicolumn{2}{|c|}{ Mulheres } \\
\hline & OR ajustado * & IC95\% & OR ajustado ** & IC95\% \\
\hline \multicolumn{5}{|l|}{ Idade (anos) } \\
\hline 15 & 1,0 & - & 1,0 & - \\
\hline 16 & 1,3 & $0,4-4,1$ & 2,9 & $0,8-9,8$ \\
\hline 17 & 5,2 & $1,6-16,6$ & 6,7 & $1,9-23,1$ \\
\hline 18 & 4,2 & $1,1-16,0$ & 7,5 & $2,1-26,8$ \\
\hline 19 & 3,0 & $0,7-12,3$ & 12,3 & $2,9-53,3$ \\
\hline \multicolumn{5}{|l|}{ Estudo atual } \\
\hline Não & 3,8 & $1,3-11,4$ & - & - \\
\hline Sim & 1,0 & - & - & - \\
\hline \multicolumn{5}{|l|}{ Tipo de domicílio } \\
\hline Próprio & - & - & 1,0 & - \\
\hline Ocupado & - & - & 2,9 & $1,2-6,8$ \\
\hline Alugado & - & - & 1,6 & $0,4-5,9$ \\
\hline \multicolumn{5}{|l|}{ Mãe concorda que adolescentes tenham vida sexual } \\
\hline Não & 1,0 & - & - & - \\
\hline Sim & 3,3 & $1,4-7,6$ & - & - \\
\hline \multicolumn{5}{|l|}{ Pai gostaria que filho(a) iniciasse a vida sexual } \\
\hline Após casamento & 1,0 & - & - & - \\
\hline Independentemente do casamento & 3,1 & $1,1-12,8$ & - & - \\
\hline \multicolumn{5}{|l|}{ Namoro anterior } \\
\hline Não & 1,0 & - & 1,0 & - \\
\hline Sim & 7,2 & $1,2-41,6$ & 16,2 & $1,9-140,9$ \\
\hline \multicolumn{5}{|l|}{ Namoro atual } \\
\hline Não & 1,0 & - & 1,0 & - \\
\hline Sim & 6,2 & $2,2-17,7$ & 5,6 & $2,6-11,8$ \\
\hline \multicolumn{5}{|l|}{ Irmão(ã) que já engravidou antes de uma união } \\
\hline Não & - & - & 1,0 & - \\
\hline Sim & - & - & 2,5 & $1,1-5,8$ \\
\hline Não tem irmão(ã) maior que dez anos de idade & - & - & 1,7 & $0,6-5,3$ \\
\hline
\end{tabular}

* Modelo final ajustado por: idade, estudo atual, namoro anterior, namoro atual, concordância da mãe com que adolescentes tenham vida sexual e momento em que o pai gostaria que filho(a) iniciasse a vida sexual. Teste Hosmer-Lemeshow: $p=0,759$;

** Modelo final ajustado por: idade, tipo de domicílio, namoro anterior, namoro atual, irmão(ã) que já engravidou antes de uma união. Teste Hosmer-

Lemeshow: $p=0,523$.

adolescentes tenham vida sexual e o fato de que o pai gostaria que seu filho iniciasse a vida sexual independentemente do casamento.

Entre as adolescentes do sexo feminino, não permaneceu no modelo final como associado à iniciação sexual nenhuma variável relativa às mães ou pais, mas o fato de habitar um domicílio ocupado e a presença de irmão ou irmã que já haviam passado por uma gestação antes de uma união conjugal foram associados estatisticamente ao início da vida sexual.

\section{Discussão}

O perfil dos sujeitos entrevistados, caracterizado pela considerável proporção de adolescentes ausentes do sistema educacional, moradores de domicílios ocupados de uma região periférica do Município de São Paulo, com pais e mães de baixa escolaridade, indicou tratar-se de um grupo cuja inserção social pode ser considerada precária. A situação sócio-econômica desfavorecida dos entrevistados não permite generalizações a todos os adolescentes residentes no Município de São Paulo, porém os resultados podem ser 
semelhantes para aqueles que vivem nas mesmas condições de vida nessa cidade.

Fatores individuais associados ao início da vida sexual

A idade foi associada ao início da vida sexual, ou seja, ter 17 anos de idade ou mais elevou a chance de iniciação sexual, independentemente de ser do sexo feminino ou masculino, o que está em acordo com vários outros estudos 4,7,8,9.

A idade mostrou ser um marcador importante da iniciação sexual e deveria ser considerada muito seriamente na elaboração e implementação de estratégias de promoção da saúde reprodutiva e sexual do grupo adolescente, sem que haja, contudo, generalizações. Essas estratégias necessitariam alcançar não apenas o adolescente engajado em atividade sexual ou tendo iniciado sua vida reprodutiva, mas também aquele que ainda não a iniciou - por isso a importância de se conhecer a idade da primeira relação sexual -, estimulando atitudes responsáveis em relação à sexualidade e reprodução, preparando-o, assim, para o início de uma vida sexual sem riscos.

O fator mais intensamente associado à iniciação sexual dos adolescentes de 15 a 19 anos de idade foi a relação de namoro, independentemente do sexo dos entrevistados. As questões referentes ao namoro são pouco exploradas por estudos conduzidos com populações adolescentes, e é preciso lembrar que grandes inquéritos realizados no passado permitiram analisar os dados somente segundo o estado conjugal, esquecendo que o namoro - em conjunto com o ficar - é o tipo de relacionamento afetivo e amoroso mais freqüente na adolescência. É durante o namoro que os caminhos são abertos para uma mútua exploração sexual (Schwartz 11 destacou que, muito antes da primeira relação sexual, a maior parte dos adolescentes já se engajou em experiências ditas pré-sexuais, como carícias e toques mais íntimos), levando ao aprofundamento da intimidade até a opção pela relação sexual.

É possível, pois, considerar que o namoro necessitaria estar entre os tópicos abordados nas intervenções realizadas com os adolescentes justamente por se constituir em um espaço de exercício das relações entre homens e mulheres que, sejam mais igualitárias ou mais hierarquizadas, poderão ser transpostas às atitudes e práticas sexuais e contraceptivas.

Vários estudos relacionaram a frágil inserção social como fator de risco ao início da vida sexual $2,5,7,8,9,12$, o que vai ao encontro dos achados no grupo de adolescentes do sexo feminino, em que a única variável proxy à inserção social que permaneceu independente na análise múltipla foi a propriedade do domicílio. Assim, as garotas que habitavam domicílios ocupados mostraram uma chance quase três vezes maior de ter iniciado a vida sexual do que as que habitavam domicílios próprios, confirmando a precariedade da inserção social como um aspecto que agrega mais chance de iniciação sexual.

Ainda em relação à inserção social, constatou-se que o fato de não estudar foi associado à iniciação sexual entre o grupo de adolescentes do sexo masculino; tal fenômeno foi observado no grupo feminino somente na análise univariada. Esse achado está em acordo com Schvaneveldt et al. 13 e Wellings et al. 14 que, respectivamente na Suécia e no Reino Unido, encontraram uma maior chance de iniciação sexual entre os adolescentes que já haviam abandonado ou que tinham vínculos frágeis com a escola. Pode-se concluir, assim, que investir na promoção da saúde sexual e reprodutiva de adolescentes significa, com certeza, investir propriamente em educação formal.

Na população entrevistada, não foi observada qualquer diferença no início da vida sexual segundo a cor auto-referida, provavelmente em virtude de este grupo habitar um espaço geográfico reduzido e configurar-se em uma população relativamente homogênea sócio-demograficamente. Tal resultado está em desacordo com praticamente toda a literatura pesquisada que considerou as questões de raça e cor em suas análises 2,4,8,15, com exceção de Leite et al. 5, que enfatizaram que a cor perde a significância quando ajustada pela escolaridade, ou seja, a cor é um marcador social importante, mas provavelmente pouco específico na presença de condições semelhantes de vida, perdendo sua força de influência nas questões do comportamento sexual.

\section{Fatores familiares associados ao início da vida sexual}

Em momento algum do desenvolvimento do modelo múltiplo final, os fatores relacionados aos pais e mães foram associados ao início da vida sexual entre as mulheres. Mesmo que na caracterização do relacionamento entre os pais (mãe e pai) e as filhas tenha sido verificado que as garotas não percebem uma naturalidade em relação a práticas sexuais pré-matrimoniais, em concordância com Huerta-Franco et al. 16, não foi observado qualquer tipo de associação com a iniciação sexual. Entretanto, é possível considerar que, de certa forma, os pais e mães transmitem uma idéia positiva quanto à iniciação sexual dos filhos homens e, nesta população, tais fatores foram positivamente associados ao início da vida sexual. 
Um outro fator associado à iniciação sexual descrito pela literatura é a estrutura familiar, entendida como a coabitação do jovem. No entanto, os dados obtidos neste estudo não foram condizentes com os apontamentos da literatura pesquisada 2,8,9,12,17. Já os aspectos relacionados à comunicação pais-filhos foram investigados por meio de questionamentos, verificando se os adolescentes consideravam ter abertura para conversar assuntos relativos a sexo com seus pais e mães. Diferentemente da maior parte da literatura consultada $10,16,18$, porém coincidente com o relatado por Wellings et al. 14 , tais aspectos não foram, em nenhum momento, significativos na iniciação sexual. Pode ser que não tenha realmente havido, na população investigada, qualquer traço de influência da comunicação pais-filhos na iniciação sexual dos adolescentes. Contudo, não se pode perder de vista que a influência parece se dar por meio da sociabilidade e convivência, quando os valores são transmitidos não apenas verbalmente ou por meio de diálogos voltados especificamente para assuntos relativos a sexo.

Mas pode ser também que os dados acerca da comunicação com os pais não tenham sido devidamente investigados em virtude de o questionário ter sido estruturado, refletindo a necessidade de novas investigações que aprofundem o tema da comunicação e interação pais-filhos nas questões do comportamento sexual de adolescentes brasileiros, utilizando, para isso, métodos de cunho qualitativo ou adaptações de escalas já testadas e validadas em outros estudos. De qualquer forma, a baixa proporção de adolescentes que relataram ter abertura para perguntar assuntos relativos a sexo a seus pais faz crer que ainda há um longo caminho a ser percorrido nas vivências pais-filhos em busca de um relacionamento mais íntimo e positivo.

A falta de supervisão parental apareceu como fator associado à ocorrência da primeira prática sexual somente na análise univariada. Observouse que mães consideradas não rígidas (liberais ou meio-termo) pelos adolescentes aumentavam a chance de iniciação sexual, tendo como referência mães rígidas. Vale lembrar que a supervisão paterna não mostrou ter qualquer tipo de associação com a iniciação sexual dos filhos (homens e mulheres), talvez porque são as próprias mães que assumem a tarefa de supervisionar e responder às demandas dos filhos adolescentes. É interessante a aparente irrelevância de variáveis que dizem respeito ao relacionamento pai-filha entre os fatores associados à iniciação sexual das mulheres, tendo a ver, possivelmente, com a ausência de diálogos e participação do pai na vida de seus filhos. Esse fenômeno pode ter sido observado porque o papel de controle da sexualidade dos filhos é tarefa assumida pela mãe 19, e os pais são geralmente pouco participativos nas conversas sobre sexualidade e contracepção no bojo das famílias 20 .

Foi observada, também, associação entre a presença de irmão(ã) que já passou por uma gravidez antes de uma união e o início da vida sexual, todavia tal variável mostrou-se independentemente associada apenas entre as mulheres. East \& Kiernan 21 observaram uma maior tendência de iniciação sexual em idades mais jovens entre adolescentes cujos(as) irmãos(ãs) passaram por uma gravidez ainda na adolescência. Isso sugere que possa haver uma conseqüente naturalização da prática sexual na adolescência pela família que depara com a gestação adolescente, redefinindo, a partir de tal evento, o que é aceitável e tolerável no comportamento sexual dos adolescentes, podendo influenciar, inclusive, em seu grau de autonomia em relação às práticas afetivo-amorosas e sexuais.

Esse também pode ser considerado um marcador importante para os profissionais que atuam no campo da saúde reprodutiva, pois, na presença de uma gravidez na adolescência, os serviços de saúde não devem se restringir apenas a assistir adequadamente mãe-pai-filho, mas ampliar sua atenção à família, especialmente aos outros irmãos que se encontram na adolescência, no sentido de promover uma vida sexual e reprodutiva saudável e livre de riscos.

$\mathrm{O}$ relato de que a maioria dos amigos dos homens já havia iniciado a vida sexual foi associado à iniciação da vida sexual na análise univariada, coerentemente com os estudos 4,7,22,23 que apontaram a intensa influência dos pares no comportamento sexual de adolescentes, incluindo a primeira relação sexual. Os pares podem ter exercido uma certa influência no comportamento sexual dos adolescentes por meio de um código de condutas e valores não identificados, porém tanto as questões individuais, entre homens e mulheres, quanto questões familiares, principalmente entre os homens, mostraram-se, de fato, independentemente associadas ao início da vida sexual.

As opiniões dos adolescentes revelaram, portanto, que há uma diferença de atitudes e expectativas maternas e paternas em relação à conduta feminina e masculina em face da sexualidade, ou seja, os garotos parecem sentir-se mais liberados a iniciar a vida sexual independentemente do casamento, ao passo que as garotas pressentem que tal prática está em desacordo com o desejo de seus pais e mães, respondendo, muito provavelmente, à lógica das relações de gênero. Mesmo assim, tais expectativas não parecem ter influen- 
ciado na iniciação sexual das mulheres, levando a crer que outros sujeitos, entre os quais irmãos e namorados, podem ter exercido um papel mais determinante em sua iniciação sexual do que os próprios pais.

Tais achados indicam novos caminhos a serem percorridos nas ações de pesquisa e atenção básica à saúde que tenham como sujeitos os adolescentes, principalmente aqueles pertencentes a grupos sociais mais desfavorecidos. O olhar voltado à família como instrumento de promoção da saúde sexual e reprodutiva de adolescentes faz mais sentido ainda se relembrarmos que há, no país, uma política de reorientação da atenção primária à saúde voltada à família, que é o PSF,

\section{Resumo}

Com o objetivo de analisar os aspectos individuais e familiares associados ao início da vida sexual, foram entrevistados, entre junho e dezembro de 2002, 383 adolescentes solteiros entre 15 e 19 anos de idade, residentes na área de abrangência de uma unidade de saúde da família da zona leste do Município de São Paulo, Brasil. Os dados foram analisados por meio de regressão logística múltipla separadamente para homens e mulheres. Os resultados mostraram que o namoro e a idade foram associados a início da vida sexual dos adolescentes. No entanto, somente entre os homens, observou-se como fatores associados variáveis relacionadas aos pais e mães e, apenas entre as mulheres, variáveis relacionadas à propriedade do domicílio e aos irmãos. Dessa forma, o namoro e as questões familiares, tais como os valores parentais no tocante às práticas sexuais de adolescentes e a presença de irmão(ã) que já passou por gravidez antes de uma união, são aspectos que necessitam ser incorporados na formulação de políticas de saúde reprodutiva e sexual voltadas aos adolescentes, pois mostraram ser determinantes na iniciação sexual dos jovens entrevistados.

Comportamento Sexual; Saúde Sexual e Reprodutiva; Adolescente já implantado, em maior ou menor extensão, em todas as regiões do país.

Os resultados salientam contextos importantes que parecem ter um forte significado na iniciação sexual, como o namoro, as gestações de irmãos ainda adolescentes e os valores e atitudes maternos e paternos acerca da sexualidade. Estes são aspectos presentes na vida de qualquer adolescente, seja oriundo de camadas sociais mais favorecidas, seja pertencente a camadas sociais mais empobrecidas e, por isso, necessitariam ser considerados como elementos fundamentais para constituir a base de ações de promoção da saúde do adolescente.

\section{Colaboradores}

A. L. V. Borges trabalhou na concepção do estudo, análise e interpretação dos resultados e redação do artigo. M. R. D. O. Latorre colaborou na análise estatística dos dados. N. Schor contribuiu na concepção do estudo e interpretação dos resultados. 


\section{Referências}

1. Aquino EML, Heilborn ML, Knauth D, Bozon M, Almeida MC, Araújo J, et al. Adolescência e reprodução no Brasil: a heterogeneidade dos perfis sociais. Cad Saúde Pública 2003; 19 Suppl 2:S377-88.

2. Ministério da Saúde/Centro Brasileiro de Análise e Planejamento. Pesquisa sobre comportamento sexual e percepções da população brasileira sobre HIV/AIDS. Brasília: Programa Nacional de DST e AIDS, Ministério da Saúde; 2000.

3. Forste R, Haas DW. The transition of adolescent males to first sexual intercourse: antecipated or delayed? Perspect Sex Reprod Health 2002; 34: 184-90.

4. Kinsman SB, Romer D, Furstenberg FF, Schwarz DF. Early sexual initiation: the role of peer norms. Pediatrics 1998; 102:1185-92.

5. Leite IC, Rodrigues RN, Fonseca MC. Fatores associados com o comportamento sexual e reprodutivo entre adolescentes das regiões Sudeste e Nordeste do Brasil. Cad Saúde Pública 2004; 20:474-81.

6. Rich LM, Kim SB. Employment and the sexual and reproductive behavior of female adolescents. Perspect Sex Reprod Health 2002; 34:127-34.

7. Romer D, Black M, Ricardo I, Feigelman S, Kaljee L, Galbraith J, et al. Social influences on the sexual behavior of youth at risk of HIV exposure. Am J Public Health 1994; 84:977-85.

8. Santelli JS, Lowry R, Brener N, Robin L. The association of sexual behaviors with socioeconomic status, family structure and race/ethnicity among US adolescents. Am J Public Health 2000; 90: 1582-8.

9. Upchurch DM, Levy-Storms L, Sucoff CA, Aneshensel CS. Gender and ethnics differences in the timing of first sexual intercourse. Fam Plann Perspect 1998; 30:121-7.

10. Miller KS, Kotchick BA, Dorsey S, Forehand R, Ham AY. Family communication about sex: what are parents saying and what are their adolescents listening? Fam Plann Perspect 1998; 30:218-22.

11. Schwartz IM. Sexual activity prior to coital initiation: a comparison between males and females. Arch Sex Behav 1999; 28:63-9.

12. Longo LAFB. Juventude e contracepção: um estudo dos fatores que influenciam o comportamento contraceptivo das jovens brasileiras de 15 a 24 anos. Revista Brasileira de Estudos Populacionais 2002; 19:229-47.
13. Schvaneveldt PL, Miller BC, Berry EH, Lee TR. Academic goals, achievement, and age at first sexual intercourse: longitudinal, bidirectional influences. Adolescence 2001; 36:767-87.

14. Wellings K, Nanchahal K, Macdowall W, McManus S, Erens B, Mercer $\mathrm{CH}$, et al. Sexual behaviour in Britain: early heterosexual experience. Lancet 2001; 358:1843-50.

15. Brindis C. Adolescent pregnancy prevention for hispanic youth: the role of schools, families and communities. J Sch Health 1992; 62:345-51.

16. Huerta-Franco R, Léon JD, Malacara JM. Knowledge and attitudes toward sexuality in adolescents and their association with the family and other factors. Adolescence 1996; 31:179-91.

17. Kiernan KE, Hobcraft J. Parental divorce during childhood: age at first intercourse, partnership and parenthood. Popul Stud (Camb) 1997; 51:41-55.

18. Karofsky PS, Zeng L, Kosorok MR. Relationship between adolescent-parental communication and initiation of first intercourse by adolescents. J Adolesc Health 2000; 28:41-5.

19. Rieth F. Ficar e namorar. In: Bruschini C, Hollanda HB, organizadores. Horizontes plurais: novos estudos de gênero no Brasil. São Paulo: Editora 34; 1998. p. 114-33.

20. Heilborn ML. O traçado da vida: gênero e idade em dois bairros populares do Rio de Janeiro. In: Madeira FR, organizador. Quem mandou nascer mulher? Estudos sobre crianças e adolescentes pobres no Brasil. São Paulo: Editora Rosa dos Ventos; 1997. p. 291-41.

21. East PL, Kiernan EA. Risks among youths who have multiple sisters who were adolescent parents. Fam Plann Perspect 2001; 33:75-80.

22. Mott FL, Fondell MM, Hu PN, Kowaleski-Jones L, Menegham EG. The determinants of first sex by age 14 in a high-risk adolescent population. Fam Plann Perspect 1996; 28:13-8.

23. Werner-Wilson RJ. Gender differences in adolescent sexual attitudes: the influence of individual and family factors. Adolescence 1998; 33:518-31.

Recebido em 01/Fev/2006

Versão final reapresentada em 20/Jun/2006

Aprovado em 10/Jan/2007 